\title{
Some Aspects of Free Volume Studies in Molecular Substances Using Positron Annihilation Experiments
}

\author{
V.P. Shantarovich ${ }^{a}$, T. Suzuki ${ }^{b}$, N. Djourelov ${ }^{b}$, \\ A. Shimazu ${ }^{c}$, V.W. Gustov ${ }^{a}$ And I.B. Kevdina ${ }^{a}$ \\ ${ }^{a}$ N.N. Semenov Institute of Chemical Physics, Russian Academy of Sciences \\ Moscow 119991, Kosygin st. 4, Russia \\ ${ }^{b}$ High Energy Accelerator Research Organization (KEK) \\ Tsukuba, Ibaraki 305-0801, Japan \\ ${ }^{c}$ Core Technology Center, Nitto Denko Corporation \\ 1-1-2, Shimohozumi, Ibaraki, Osaka, 567-8680, Japan

\begin{abstract}
Positron annihilation lifetime spectroscopy is accepted now as a method for the studies of elementary free volumes (free volume holes) in solids, in polymers in particular. The aim of this paper is to discuss some problems, the difficulties on the way of this application and to illustrate them by several examples obtained by the authors.
\end{abstract}

PACS numbers: 78.70.Bj

\section{Introduction}

The first problem in the application of positron annihilation lifetime (PAL) spectroscopy for the study of elementary free volumes (EFV) in solids comes from inhibition of positronium formation, i.e. essential influence of small admixtures on the long-lived component intensity of the PAL spectrum. The nature of this effect and correlation of the phenomena with thermo-stimulated luminescence (TSL) are considered here along with calculation of the number density of free volume holes using characteristics of the PAL spectra in polyimides and systems with a highly developed specific surface, such as cross-linked polystyrenes (polymer sorbents) and silica based glasses. Finally, a special attention is paid to comparison of this value calculated on the bases of positron annihilation data with that found from sorption isotherms and Brunauer-Emmett-Teller (BET) theory. 


\section{Inhibition of positronium formation in polymers}

Recent results [1-3] on inhibition can be resumed in the following conclusions:

(1) Conjugated oxygen, or oxygen atom contained in the molecule with conjugated chain of the type $>\mathrm{C}=\mathrm{C}-\mathrm{C}=\mathrm{O}$ seems to be a stronger inhibitor of $\mathrm{Ps}$ formation than oxygen atom in isolated $>\mathrm{C}=\mathrm{O}$ group. Conjugated oxygen inhibits Ps formation even at room temperature (examples are Kapton and BMA/OKM-2 copolymer [2], i.e. a copolymer of butylmethacrylate with a cross-agent having two reaction centers). This structure suppresses TSL at low temperature. The last result means that the conjugated structure is a scavenger of weakly bound electrons. Coincidence Doppler broadening (CDB) measurements revealed also essential scavenging positrons in the above-mentioned polymers even at room temperature.

(2) Inconjugated oxygen in isolated $>\mathrm{C}=\mathrm{O}$ groups remarkably inhibits $\mathrm{Ps}$ formation on weakly bound electrons, only at low temperature (ethylene (E)/MMA copolymer). This effect is essentially limited and saturates at a certain level or changing slightly at high concentrations of inhibitor. Inconjugated oxygen is not able to suppress considerably the intensity of TSL, and, therefore, the main reason of some inhibition of Ps formation consists in trapping of positrons. Probability of $\mathrm{e}^{+}$annihilation in the bound state is affected in this case by temperature (temperature dependent scavenging of positrons in E/MMA3\% copolymer, Fig. 1a, b).
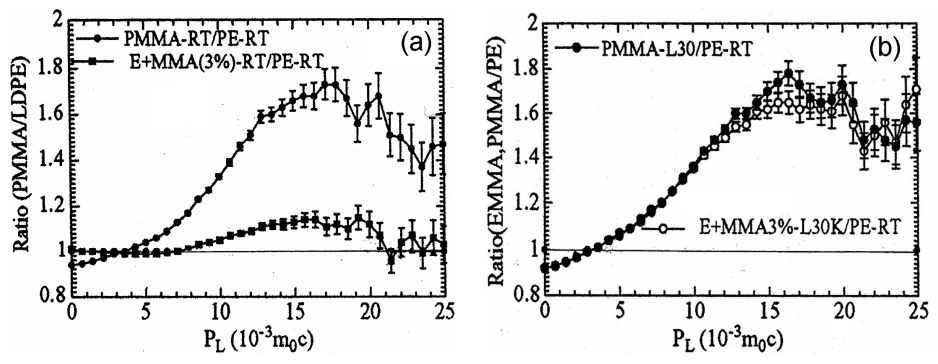

Fig. 1. (a) The ratios of coincidence Doppler broadening (CDB) curves: polymethylmetacrylate to polyethylene (PMMA/PE) and copolymer of ethylene containing 3\% methylmetacrylate to $\mathrm{PE}$ (E+MMA3\%/PE) at RT. (b) CDB ratios (to PE at $\mathrm{RT}$ ) for the same samples in light $(\mathrm{L})$ at $30 \mathrm{~K}[3]$.

(3) The reason of limited inhibition in E/MMA copolymer at low temperature and absence of inhibition in this system at RT may be found in some energy distribution of $\mathrm{e}^{+}$inside and outside the spur. Inside the spur, before Ps formation, positrons have a higher, epithermal energy and therefore they cannot be trapped. They relax while going outside the spur, and some of them become finally trapped. This is detected by CDB but does not influence Ps formation.

(4) The effects discussed above are important in positron annihilation experiments in polymers, since carbonyl groups are produced readily in the interaction of radiation products with dissolved oxygen and influence Ps formation. 


\section{Concentration and size distribution of elementary free volumes}

The above-mentioned interactions and examples, when long-lived o-Ps component intensity $I_{3}$ is determined by the density of electrons in the spur rather than by the amount of the free volume holes, make this intensity an unacceptable parameter for the free volume studies. Alternative approaches to the problem are illustrated on example of polyimides (temperature dependence experiments [4-9]) and on example of low-density cross-linked polymeric sorbents [10-17] (Table),

TABLE

PATFIT and MELT results for the lifetime spectra (first and second lines for RT and LT, correspondingly) of polymeric sorbents described in [11-13]. Letters $\rho$ and $S$ with subscripts are used to denote density (in $\mathrm{g} / \mathrm{cm}^{3}$ ) and specific surface of the samples (in $\mathrm{m}^{2} / \mathrm{g}$ ) measured in two different ways [11].

\begin{tabular}{|c|c|c|c|c|c|}
\hline Sorbent & Temp. & $\begin{array}{l}\tau_{3}, \mathrm{~ns} \\
I_{3}, \%\end{array}$ & $\begin{array}{l}\tau_{4}, \mathrm{~ns} \\
I_{4}, \%\end{array}$ & $\begin{array}{l}\tau_{5}, \mathrm{~ns} \\
I_{5}, \%\end{array}$ & $\begin{array}{c}\chi^{2} / \nu \\
I_{3}+I_{4}+I_{5}, \%\end{array}$ \\
\hline \multirow{4}{*}{$\mathrm{CPS}(0.3) 150 \mathrm{E}$} & \multirow{4}{*}{$\mathrm{RT}$} & $2.00 \pm 0.14$ & $8.91 \pm 0.2$ & $32.00 \pm 0.59$ & 1.117 \\
\hline & & $4.86 \pm 0.19$ & $6.15 \pm 0.24$ & $14.39 \pm 0.34$ & 25.40 \\
\hline & & 1.99 & 7.83 & 30.20 & 1.193 \\
\hline & & $4.4 \pm 0.4$ & $5.4 \pm 0.5$ & $15.0 \pm 0.7$ & 24.8 \\
\hline \multirow{4}{*}{$\begin{array}{l}\rho=0.71 \\
S_{S}=1300 \\
S_{\mathrm{BET}}=972[2]\end{array}$} & \multirow{4}{*}{ LT } & $1.93 \pm 0.11$ & $8.64 \pm 0.41$ & $66.02 \pm 1.4$ & 1.071 \\
\hline & & $4.77 \pm 0.15$ & $5.16 \pm 0.14$ & $12.38 \pm 0.09$ & 22.3 \\
\hline & & 2.11 & 6.91 & 49.30 & 1.314 \\
\hline & & $3.6 \pm 0.5$ & $4.4 \pm 0.6$ & $9.3 \pm 3.3$ & 17.3 \\
\hline \multirow{4}{*}{ LPS150X } & \multirow{4}{*}{ RT } & $2.24 \pm 0.16$ & $10.86 \pm 0.81$ & $60.35 \pm 0.85$ & 1.094 \\
\hline & & $4.08 \pm 0.15$ & $4.93 \pm 0.18$ & $27.89 \pm 0.21$ & 36.9 \\
\hline & & 1.98 & 7.67 & 64.5 & 1.190 \\
\hline & & $3.4 \pm 0.5$ & $4.2 \pm 2.1$ & $27.4 \pm 2.2$ & 35.0 \\
\hline \multirow{4}{*}{$\begin{array}{l}\rho=0.62 \\
S_{S}=1360 \\
S_{\mathrm{BET}}=965[2]\end{array}$} & \multirow{4}{*}{ LT } & $2.32 \pm 0.13$ & $10.59 \pm 0.71$ & $70.13 \pm 1.22$ & 1.103 \\
\hline & & $5.09 \pm 0.16$ & $5.00 \pm 0.16$ & $23.36 \pm 0.15$ & 33.45 \\
\hline & & 2.69 & 10.55 & 82.22 & 1.391 \\
\hline & & $4.9 \pm 0.4$ & $4.4 \pm 0.5$ & $20.4 \pm 1.6$ & 29.70 \\
\hline \multirow{4}{*}{ LPS200X } & \multirow{4}{*}{ RT } & $1.46 \pm 0.30$ & $7.43 \pm 0.81$ & $73.36 \pm 0.94$ & 1.076 \\
\hline & & $2.33 \pm 0.38$ & $2.80 \pm 0.18$ & $31.70 \pm 0.11$ & 36.83 \\
\hline & & 1.89 & 7.83 & 74.72 & 1.165 \\
\hline & & $1.9 \pm 0.6$ & $2.8 \pm 0.3$ & $27.7 \pm 0.2$ & 32.40 \\
\hline \multirow{4}{*}{$\begin{array}{l}\rho=0.51 \\
S_{S}=1390 \\
S_{\mathrm{BET}}=973\end{array}$} & \multirow{4}{*}{ LT } & $2.03 \pm 0.17$ & $10.64 \pm 0.83$ & $94.86 \pm 1.92$ & 1.083 \\
\hline & & $2.91 \pm 0.13$ & $3.61 \pm 0.13$ & $27.88 \pm 0.10$ & 34.4 \\
\hline & & 2.77 & 11.99 & 100.13 & 1.331 \\
\hline & & $2.8 \pm 0.3$ & $3.5 \pm 0.6$ & $21.5 \pm 0.6$ & 27.8 \\
\hline
\end{tabular}


where information on the specific surface $(S)$ and density $(\rho)$ becomes very useful. The number $N_{5}=0.15 \times 10^{20} \mathrm{~cm}^{-3}$ was obtained for LPS200X. The names of the sorbents are explained elsewhere [10]. The largest free volume holes in the polymer sorbents were big enough (in LPS200X at RT, $\tau_{5}=73-75 \mathrm{~ns}$, and, according to Tao-Eldrup equation, $R_{5}=20 \AA$ ) for comparison with the data of nitrogen sorption experiments. The experiments were accomplished by the Nitto Denko Corporation (Japan) and treated using BET theory [14]. Results for LPS200X are given in Fig. 2 and they do not contradict to the PAL estimations given above, though $R_{5}=20 \AA$ is a little bit too large. This comparison along with a discussion of temperature dependence (TD) of annihilation characteristics (Fig. 3) were useful for checking possibility to apply contemporary theoretical models, connecting EFV size and positronium lifetimes, to our experimental results. We mean here extended Tao-Eldrup (ETE) model suggested by Goworek et al. [16, 17] and so-called "classical regime", considering Ps atom as a classical particle in a large hole $[18,19]$. Analysis of our TD-data shows that the classical free path concept

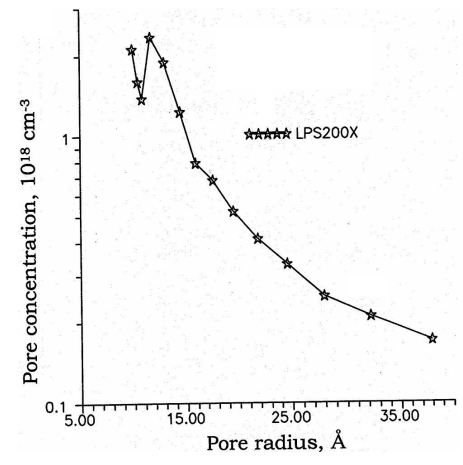

Fig. 2. Distribution of the free volume holes sizes in polymeric sorbent LPS200X found from the sorption experiments.

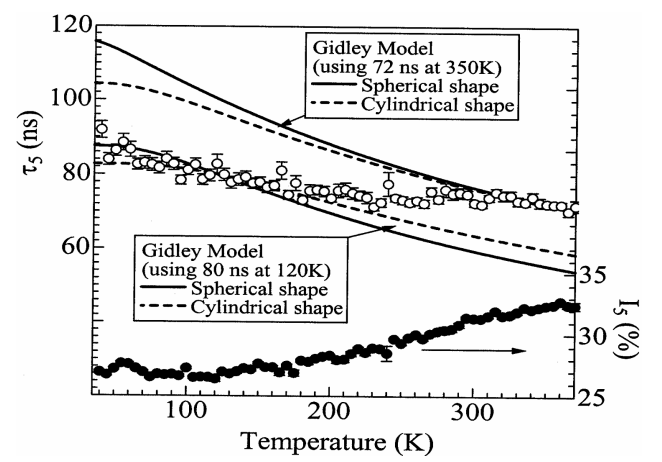

Fig. 3. Temperature dependence of the longest-lived $o$-Ps component $\tau_{5}, I_{5}$ for LPS200X (PATFIT data). Solid lines illustrate different attempts to describe temperature dependence of $\tau_{5}$ in terms of the classical particle model $[18,19]$. 
for Ps lifetime in a rectangular pore, as well as its modification for spherical or cylindrical pore in CPS150X [13], LPS200X (this work), and also in silica-based glasses (see Fig. 2 in Ref. [15]), though predicting a decrease in the longest lived $o$-Ps lifetime on heating, does not give a good enough fitting to the experimental points over the entire temperature range between 50 and $350 \mathrm{~K}$. The slope of experimental dependence is too flat compared to the theory. For example (LPS200X, Fig. 3), if the model curve is normalized on high-temperature data, an increase in experimentallifetime at low temperature is not as strong as it is expected from the theory. For silica-based glasses and polystyrenes, an explanation of this discrepancy was found $[10,11,15]$ in combination of the "large hall" effect with chemical interaction of positronium with radicals induced by irradiation and stored in a sample during the experiment with positron source at low temperature or with atmospheric oxygen strongly trapped between aromatic rings. However, another discrepancy comes out when the estimations of the pore size found on the bases of the ETE model and sorption experiments are compared. The ETE model [17] considers Tao-Eldrup equation as a limiting case of zero temperature. If this idea is followed and we apply this equation to our LT data $\left(\tau_{5}=100 \mathrm{~ns}\right.$ in LPS200X at $50 \mathrm{~K})$ the pore radius larger than $25 \AA$ is obtained. This size is poorly represented in the distribution in Fig. 2 and demonstrate the discrepancy between PAL and sorption data or, more exactly, between the sorption data and results of theoretical estimations made on the bases of the PAL data.

The results obtained show that the effects of Ps annihilation in the large free volume holes are too complicated and combined PAL and sorption experiments can be very promising for elucidation of this problem.

\section{Acknowledgments}

Some works reported in this paper were supported in part by Russian Foundation for Basic Research (RFBR), grant No 02-03-33061.

\section{References}

[1] Y. Nagai, T. Nonaka, M. Hasegava, Y. Kobayashi, C.L. Wang, W. Zheng, C. Zheng, Phys. Rev. B 60, 11863 (1999).

[2] V.P. Shantarovich, T. Suzuki, C. He, V.W. Gustov, Radiat. Phys. Chem. 67, 15 (2003).

[3] T. Suzuki, C. He, V. Shantarovich, K. Kondo, E. Hamada, M. Matsuo, M. Lin, Y. Ito, Radiat. Phys. Chem. 66, 161 (2003).

[4] D. Dlubek, K. Saarinen, H.M. Fretwell, Polym. Sci. B, Polym. Phys. 36, 1513 (1998).

[5] J. Kristiak, P. Bandzuch, O. Sausa, J. Zrubkova, J. Bartos, Mater. Sci. Forum 363-365, 269 (2001). 
[6] V.P. Shantarovich, T. Suzuki, C. He, Y. Ito, Y.P. Yampolskii, A.Yu. Alentiev, Radiat. Phys. Chem 73, 45 (2005).

[7] H.A. Hristov, B. Bolan, A.F. Yee, L. Xie, D.W. Gidley, Macromolecules 29, 8507 (1996).

[8] R.F. Boyer, R. Simha, J. Polym. Sci. (Polym. Lett. Ed.) B 11, 33 (1973).

[9] G. Dlubek, V. Bondarenko, J. Pionteck, M. Supej, A. Watzler, R. Krauze-Rehberg, Polymer 44, 1921 (2003).

[10] V.P. Shantarovich, T. Suzuki, C. He, V.A. Davankov, A.V. Pastukhov, M.P. Tsyurupa, K. Kondo, Y. Ito, Macromolecules 35, 9723 (2002).

[11] V.P. Shantarovich, T. Suzuki, C. He, N. Djourelov, I.B. Kevdina, V.A. Davankov, A.V. Pastukhov, Y. Ito, Mater. Sci. Forum 445-446, 346 (2004).

[12] V.P. Shantarovich, T. Suzuki, C. He, I.B. Kevdina, V.A. Davankov, A.V. Pastukhov, M.P. Tsyurupa, Khimiya Vysokih Energii (High Energy Chemistry) 33, 274 (2004) (in Russian).

[13] C. He, T. Suzuki, V.P. Shantarovich, K. Kondo, Y. Ito, Chem. Phys. 286, 249 (2003).

[14] S.J. Gregg, K.S.W. Sing, Absorption, Surface and Porosity, 2nd ed., Academic Press, London 1984.

[15] N. Djourelov, T. Suzuki, V. Shantarovich, K. Kondo, Radiat. Phys. Chem. 72, $723(2005)$

[16] T. Goworek, K. Ciesielski, B. Jasinska, J. Wawryszczuk, Chem. Phys. 230, 305 (1998).

[17] B. Jasinska, A.E. Koziel, T. Goworek, J. Rdioanal. Nucl. Chem. 210, 617 (1996).

[18] D.W. Gidley, W. Frieze, T.L. Dull, A.F. Yee, E.T. Ryan, H.M. Ho, Phys. Rev. B 60, 5157 (1999).

[19] T.L. Dull, W.E. Frieze, D.W. Gidley, J.N. Sun, A.F. Yee, J. Phys. Chem. B 105, 4657 (2001). 